\title{
O perfil socioeconômico dos MEIs passo-fundenses: uma análise no ano de 2013
}

\author{
Rubiele Liandra Tartas* \\ Amanda Guareschi** \\ Nadia Mar Bogoni****
}

\begin{abstract}
Resumo
Este artigo tem o objetivo de verificar a concepção dos indivíduos diante da sua formalização como microempreendedores individuais em Passo Fundo no ano de 2013. Considerase o tema relevante devido ao seu papel dinamizador do desenvolvimento regional e por descrever o impacto dessa política pública na cidade. Com uma pesquisa quantitativa, verificou-se a satisfação dos novos empresários. A pesquisa alcançou uma amostragem aleatória de cem entrevistados do município de Passo Fundo, que foram contatados por telefone, os dados foram tabulados com ajuda da estatística descritiva simples. Com os resultados, evidenciou-se a satisfação positiva dos donos de negócios, e a análise de perfil mostrou que o microempreendedor individual é um instrumento de incentivo ao empreendedorismo e à formalização.
\end{abstract}

Palavras-chave: Microempreendedor individual. Formalização. Satisfação.

* Mestranda em Economia - Integração Econômica Internacional - na Universidade do Vale do Rio dos Sinos. Graduada em Ciências Econômicas pela Universidade de Passo Fundo (2013). E-mail: rubieletartas@hotmail.com

** Professora na Universidade de Passo Fundo. Economista Corecon RS 7.600. Mestra em Desenvolvimento Rural pela Universidade Federal do Rio Grande do Sul. E-mail: amandaguareschi@yahoo. com.br

*** Graduada em Ciências Econômicas pela Universidade de Passo Fundo (2000). Especialista em Gestão e Controle na Administração Pública. Mestra em Ciências Contábeis - Controladoria - pela Universidade Regional de Blumenau. E-mail: nbogoni@upf.br

http://dx.doi.org/10.5335/rtee.v21i45.6194

Submissão: 21/08/2014. Aceite: 26/02/2015. 


\section{Introdução}

As atividades econômicas em geral, com baixa produtividade, que se desenvolvem às margens da legislação, mostram-se um fenômeno histórico que está presente na economia há muito tempo. Para esse caso, conforme Silva et al. (2010), o conceito de informalidade é um instrumento explicativo, caracterizado pelo subemprego que se funde ao desemprego, pela falta do direito de proteção ao trabalhador.

Ulyssea (2006) destaca que, para alguns autores, o conceito de informalidade relaciona-se àqueles trabalhadores que não contribuem com a Previdência Social. Segundo ele, a informalidade no Brasil define-se pela posse da carteira de trabalho assinada, direito de todo trabalhador.

Sasaki e Vasques-Menezes (2012), em seu artigo, destacam que um conceito indefinido para informalidade dificulta a compreensão do assunto assim como a elaboração de políticas públicas. É uma atividade que está exclusa dos benefícios gerados pela relação de emprego formal, desprotegido pela legislação, afirmam os autores.

Do ponto de vista de Ulyssea (2006), um dos motivos que pode explicar a informalidade é a diferenciação de salários. $O$ autor evidencia que alguns estudos da literatura empírica traziam como inferior o salário dos trabalhadores informais, contudo, estudos mais recentes o apresentam, algumas vezes, superior, ou com variações, dependendo do grupo de trabalho analisado.

Entretanto, mesmo após a elaboração concreta de uma definição para o termo pela Organização Internacional do Trabalho, que conceituou informalidade como um setor sem barreiras para a entrada de subsídios por meio de recursos domésti$\cos$, de posse individual e que atua em pequena escala em um mercado competitivo e sem regulamentação, optou-se por deixar de lado a definição do termo e passou-se a interpretar a informalidade pelo viés de sua função no mercado de trabalho, explica Silva et al. (2002).

Um dos benefícios que a formalidade oferece ao trabalhador é a Carteira de Trabalho e Previdência Social. Segundo informações do Portal do Trabalho e Emprego, esse documento é indispensável ao trabalhador, pois nele espelha-se sua vida profissional e oferece-se acesso a diretos básicos, como aposentadoria; recolhimento para o Fundo de Garantia por Tempo de Serviço, seguro-desemprego, auxílio maternidade; entre outros benefícios. Outra vantagem é o acesso à Previdência Social, que oferece seguro social ao contribuinte. Conforme consta no endereço eletrônico do Ministério do Trabalho e Previdência Social, a renda transferida pela Previdência Social substitui, quando necessário, a renda do contribuinte devido à 
perda de sua capacidade de trabalho por doença, invalidez, idade avançada, entre outros fatores.

Em contrapartida a esses benefícios, a partir dos anos 1990, percebe-se o aumento do número de trabalhadores sem carteira assinada, ou por conta própria, devido, principalmente, à redução dos postos de trabalhos manuais na indústria, que foram sendo substituídos pela tecnologia, exigindo menos mão de obra (SILVA et al., 2002).

Outro fator, citado por Sasaki e Vasques-Menezes (2012), indica que esse aumento de trabalhadores informais se deve ao excesso de regulamentação do mercado de trabalho e de burocracia. Os autores afirmam que uma alternativa viável seria uma proposta de redução das barreiras de acesso à formalização para as micro e pequenas empresas e de maior flexibilização na legislação trabalhista, como alternativa para gerar novos empregos.

O governo, ciente dessa grande quantidade de trabalhadores que atuavam por conta própria, instituiu a Lei Complementar n⿳⼈ 128/2008 e criou a figura do microempreendedor individual (MEI), com vigência a partir de $1^{\circ}$ de julho de 2009. De acordo com essa legislação, o MEI está enquadrado no Simples Nacional, portanto, isento do recolhimento de tributos federais, como Imposto de Renda, Programa de Integração Social (PIS), Contribuição para o Financiamento da Seguridade Social (Cofins), Imposto sobre Produtos Industrializados (IPI) e Contribuição Social sobre o Lucro Líquido (CSLL), ficando obrigado a pagar mensalmente um valor fixo de $R \$ 34,90$, se a atividade for do comércio ou da indústria, $R \$ 38,90$, se for prestação de serviços, e $R \$ 39,90$, em atividades de comércio e serviço. Esses valores se alteram anualmente, de acordo com salário mínimo vigente. Com essas contribuições em dia, o MEI terá acesso a benefícios, como auxílio maternidade, auxílio doença, aposentadoria, entre outros direitos.

Nesse cenário, a instituição de uma nova figura jurídica causa mudanças no desenvolvimento regional e na situação em que cada indivíduo se apresenta. A questão que se impõe é se essa política implementada é satisfatória e se está de acordo com as necessidades dos trabalhadores.

Dessa forma, o objetivo deste estudo consiste em verificar a percepção dos indivíduos diante de sua condição de trabalhador formal no município de Passo Fundo, no ano de 2013. Como objetivos específicos, buscou-se caracterizar o perfil socioeconômico dos MEIs entrevistados e investigar se os benefícios trazidos pelo MEI são satisfatórios como novo modelo de pessoa jurídica. 


\section{Revisão de literatura}

O presente trabalho inicia com a discussão sobre a intervenção do Estado na economia após a crise de 1929, procurando refrear o alto índice de desemprego que havia naquele período. Depois, apresenta-se a figura do empresário e a empresa, e como podem ser definidas. Então, discute-se sobre os efeitos da informalidade na economia brasileira, finalizando com a apresentação do MEI, uma alternativa para a categoria do subemprego.

\subsection{A intervenção do Estado no desemprego}

De acordo com Carvalho et al. (2008), para os economistas clássicos, antes da Grande Depressão de 1929, a acomodação de mercado ocorria automaticamente, causando o ajuste de pleno emprego da economia em um curto prazo de tempo. Conforme os autores, a referência que se usava era a Lei de Say - toda oferta cria a própria demanda -, argumento que até então era aceito, pois explicava que o poder de compra necessário para a absorção da demanda era gerado pela produção.

Em 1776, Adam Smith publicou sua grande obra A riqueza das nações, com a teoria da mão invisível, que impôs ordem sobre o mercado, como descrevem Kishtainy et al. (2013). Essa teoria explica que se um indivíduo age por interesse próprio, ele irá, involuntariamente, beneficiar a toda a economia.

Da mesma maneira, o escritor holandês Bernard de Mandeville exemplifica com seu poema A fábula das abelhas (1714). No poema, descreve-se uma colmeia na qual, se houvesse vícios, ou seja, um comportamento egoísta de cada abelha, haveria prosperidade, entretanto, caso trabalhassem em conjunto pelo benefício da comunidade, a colmeia desandaria, assim esclarecem Kishtainy et al. (2013).

Poucas vezes Smith menciona, em sua obra de cinco volumes, a teoria da mão invisível, mesmo assim, quase sempre ela está presente, comentam Kishtainy et al. (2013). Smith afirma que:

[...] as economias de mercado geram rendimentos justos que podem ser gastos em bens, num "fluxo circular" sustentável, em que o dinheiro pago em salários volta para a economia quando o trabalhador paga pelos bens e será devolvido em salários, repetindo o processo (1776 apud KISHTAINY et al., 2013, p. 58, grifo dos autores).

Assim sendo, todo o capital investido na infraestrutura de produção aumenta o número de mão de obra exigido, possibilitando, com isso, aos empregadores arcar com salários mais altos, caso haja a opção de pagar mais, eles o farão, pois terão de competir entre si pelos trabalhadores. 
Desde Adam Smith, considerado o primeiro economista, até John Maynard Keynes, considerado pai da macroeconomia, os economistas considerados clássicos focavam-se na produção e na eficiência econômica. Para eles, os preços de mercado e os salários cairiam em épocas de recessão com o objetivo de trazer a economia de volta à situação de pleno emprego em um curto prazo (CARVALHO et al., 2008). A teoria clássica foi contestada por Keynes, em 1936, em seu livro Teoria geral do emprego, do juro e do dinheiro, escrito durante a Grande Depressão. Essa obra revolucionou a maneira de se pensar a macroeconomia.

Keynes inicia sua análise a partir da Grande Depressão de 1929, pois nesse período houve uma grande queda nos preços e um aumento do valor do salário real. Isso desencadeou uma redução na contração de mão de obra, aumentando o desemprego.

A visão keynesiana resume-se como se segue:

[...] os homens de negócio produzirão apenas a quantidade de bens e serviços que eles acreditam que consumidores, investidores, governos e compradores no exterior planejam comprar. Se essa despesa agregada planejada for inferior ao nível de produto de pleno emprego da economia, o produto corrente será inferior ao seu potencial. Quando a despesa agregada é insuficiente, não existem, na economia, forças automáticas capazes de garantir o pleno emprego. Assim, será possível um período prolongado de desemprego (CARVALHO et al. 2008, p. 405).

Keynes (1936 apud CARVALHO et al., 2008), em seu modelo básico, explica que em fases de recessão, ações de política fiscal, como redução da tributação e aumento nos gastos do governo, provocam uma ampliação no efeito multiplicador, gerando aumento na demanda agregada. Essa atitude fará com que uma economia que esteja operando abaixo de sua capacidade comece a apresentar um crescimento acentuado do produto real e do emprego.

\subsubsection{Informalidade no Brasil}

Nos países em desenvolvimento, o tema informalidade só entrou em discussão a partir da década de 1960, para explicar a não inserção dos menos favorecidos nos processos produtivos. Esse assunto dividiu-se em duas correntes centrais: a de base estruturalista e a de extração marxista (COSTA, 2010).

Costa (2010) explica que a base estruturalista era representada pela ideia de que o subdesenvolvimento descendia de uma economia na qual não havia um valor relativo de troca entre o centro desenvolvido e a periferia, que deriva do excedente 
da população rural colocada em um segmento à parte na sociedade capitalista, dependendo de adequações aos requisitos para sua inserção na sociedade industrial.

Do ponto de vista marxista, Costa esclarece que a teoria é embasada na acumulação capitalista, sistema em que a informalidade não é uma derivação, mas "é resultado de um modo de acumulação capitalista, estruturado sob uma lógica de dominação das relações de produção, portanto de classe, que gera seu próprio excedente de trabalho" (2010, p. 174).

Conforme avalia Noronha (2003), na década de 1970, grande parte dos trabalhadores industriais incorporou-se ao mercado formal, diminuindo o número de trabalhadores rurais que se ocupavam em subempregos, inseridos indevidamente no mercado de trabalho. Já na década de 1980, a informalidade era tratada como um problema inerente, afirma o autor, devido ao pressuposto de que a informalidade era indício de uma economia semi-industrializada com tendência de queda, conforme fosse se desenvolvendo.

Entretanto, nos anos 1990, esse ponto de vista foi rejeitado com o aumento significativo da informalidade, conforme afirmam Meneguin e Bugarin (2008). O crescimento acentuado dessa categoria de ocupação tornou-se uma questão social a ser discutida devido à perspectiva do mercado de trabalho que a coloca em desvantagem (SASAKI; VASQUES-MENEZES, 2012).

\subsubsection{Unidades econômicas de coordenação}

Dos pontos de vista de muitos autores que discorrem sobre o tema empresa e empresário, obtêm-se diversos conceitos. Discutir-se-á, nesta seção, as definições de Faria (1960). Em seu livro, o autor conceitua empresa como uma "unidade econômica que coordena o capital, trabalho e natureza, com o propósito de transformar a riqueza em utilidade e de obter um lucro através da satisfação de uma necessidade" (1960, p. 158).

Assim, a empresa nada mais é do que uma organização que tem vida própria, que trabalha na formação de um patrimônio, tendo ao seu alcance a coordenação administrativa e a força de trabalho dinâmica. Contudo, o autor rebate que nem todas as empresas são criadas com objetivos financeiros, transformação de utilidade em riqueza ou destinada a obter lucros, citando como exemplo uma associação cultural ou um clube de futebol.

Faria (1960) define o empresário como a pessoa responsável por correr o risco da atividade executada pela empresa. Geralmente, ele é o sujeito com uma boa ideia, reputação ou iniciativa que coordena um capital, organiza a empresa com 
foco na obtenção de lucros. Seu salário é o lucro ou prejuízo obtido ao fim do período, resultado obtido no confronto entre despesa e receita, sua presença é imprescindível na organização, pois é o agente que conduz o passo a passo desempenhado pela estrutura econômica, justifica o autor.

Na obra A riqueza das nações, Adam Smith aceita a existência de três tipos de empresários: o adventurer, o projector e o undertaker (1776 apud ZEN; FRACASSO, 2008). Zen e Fracasso (2008) explicam que o adventurer é o especulador ou aventureiro, tipo de empresário que investe seu capital em negócios de alto risco, o projector segue duas correntes, tanto representa o empresário que se utiliza trapaças como o que planeja ou executa ideias honestas, e, por fim, o undertaker é aquele dedicado à realização de projetos com prudência e moderação. As autoras concluem que Adam Smith simpatizava mais com o tipo de empresário undertaker, talvez pela sua formação filosófica, já que esse tipo de empresário era caracterizado por ser menos arriscado e especulador.

\subsection{A figura do microempreendedor individual}

Como alternativa para a formalização de profissionais que exerciam suas atividades sem a cobertura dos benefícios de direito básico dos trabalhadores, e também para resolver o problema da sonegação de impostos, foi criada a lei que instituiu o microempreendedor individual, assim esclarecem Souza e Schaurich (2011).

Assim, segundo o que determina o art. 966 da Lei $\mathrm{n}^{\circ}$ 10.406, de 10 de janeiro de 2002, que institui o Código Civil:

Considera-se empresário quem exerce profissionalmente atividade econômica organizada para a produção ou a circulação de bens ou de serviços. Parágrafo único. Não se considera empresário quem exerce profissão intelectual, de natureza científica, literária ou artística, ainda com o concurso de auxiliares ou colaboradores, salvo se o exercício da profissão constituir elemento de empresa (BRASIL, 2002).

Com essa lei intenciona-se a formalização dos trabalhadores que se encontram no mercado informal, com a figura do microempreendedor individual e a opção de uma empresa com baixos custos.

\subsubsection{Objetivos da criação do microempreendedor individual}

O microempreendedor individual, como figura jurídica, entrou em vigor em

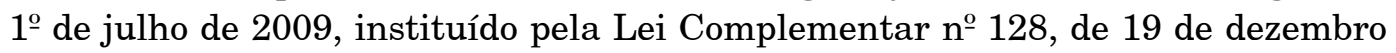
de 2008, que alterou a lei que instituiu o Simples Nacional, Lei Complementar $\mathrm{n}^{\mathrm{o}}$ 123/2008: 
Parágrafo primeiro. Para os efeitos desta Lei, considera-se MEI o empresário individual a que se refere o art. 966 da Lei no 10.406, de 10 de janeiro de 2002 - Código Civil, que tenha auferido receita bruta, no ano-calendário anterior, de até $\mathrm{R} \$ 36.000,00$ (trinta e seis mil reais), optante pelo Simples Nacional e que não esteja impedido de optar pela sistemática prevista neste artigo (BRASIL, 2008).

Enquadra-se nessa lei a pessoa física maior de 18 anos, que trabalha individualmente ou mantém até um funcionário contratado recebendo o salário mínimo ou o piso da categoria. Silva et al. (2010) explicam que, se tiver empregado, o MEI pagará mensalmente à Previdência Social o valor correspondente a $3 \%$ do salário desse funcionário, a título de contribuição patronal, além da contribuição que já é descontada como previsto em lei, em um único documento de arrecadação, que será disponibilizado pelo Comitê Nacional do Simples. Caso ocorra o afastamento legal desse colaborador, será permitida a contratação temporária de outro funcionário.

O empresário poderá desenvolver as atividades de comércio, serviço e indústria, excluindo as que estão relacionadas nos Anexos IV e V da Lei Complementar n⿳ $123 / 2008$. Outro impedimento ao enquadramento do trabalhador como MEI será no caso de o solicitante ter mais de uma empresa, outra sociedade, ou exercer profissões regulamentadas, como médicos, advogados, engenheiros, etc., complementam os autores.

As atividades que se excluem das exceções citadas serão registradas no Cadastro Nacional de Pessoas Jurídicas (CNPJ), portanto, serão consideradas pessoas jurídicas, o que lhes permite usufruir dos benefícios empresariais disponíveis, como emissão de notas fiscais para todas as transações comerciais (SILVEIRA; TEIXEIRA, 2011).

Silveira e Teixeira (2011) mencionam que o MEI desfrutará, também, dos benefícios da Previdência Social, como aposentadoria por idade, seguro por acidente de trabalho, licença maternidade, pensão por morte do segurado e auxílio-reclusão.

De acordo com o Serviço Brasileiro de Apoio à Micro e Pequena Empresa (Sebrae) (2012a), a tributação do MEI dar-se-á por recolhimento mensal dos impostos e contribuições que abranjam o Simples Nacional. Entretanto, os valores serão fixos e não dependerão da receita bruta gerada no mês, desde que o limite do faturamento, tratado no inciso I do parágrafo $1^{\circ}$, seja de $\mathrm{R} \$ 5.000,00$ (cinco mil reais), multiplicados pelos doze meses do ano-calendário. Caso a atividade tenha se iniciado durante o ano, o valor será multiplicado pelo número de meses compreendidos desde o início da atividade e o final do respectivo ano, não ultrapassando os $\mathrm{R} \$ 60.000,00$ (sessenta mil reais) por ano. O recolhimento é feito por meio de Documento de Arrecadação do Simples Nacional, obedecendo à classificação indicada no Quadro 1.

Teoria e Evidência Econômica - Ano 21, n. 45, p. 418-441, jul./dez. 2015 
Quadro 1 - Valores de arrecadação do Simples Nacional pelo MEI

\begin{tabular}{|c|c|c|}
\hline Atividade econômica & Recolhimento fixo mensal & Tributos incluídos \\
\hline $\begin{array}{c}\text { Comércio } \\
\text { Indústria }\end{array}$ & INSS $5 \%$ do salário mínimo & + ICMS: R\$ 1,00 \\
Prestação de serviços & + ISS: $\mathrm{R} \$ 5,00$ \\
\hline
\end{tabular}

Fonte: elaboração das autoras com base em dados do Sebrae (2012a).

A instituição da lei do MEI deu-se em 2008, mas passou a vigorar apenas em $1^{\circ}$ de julho de 2009. Em 2012, houve alterações nessa lei com o objetivo de ampliar os incentivos de formalização, conforme Schwingel e Rizza (2013). O Quadro 2 mostra as principais alterações ocorridas.

Quadro 2 - Alterações na legislação do MEI

\begin{tabular}{|c|c|c|}
\hline Principais alterações & Lei Complementar 123/2008 & Lei Complementar 139/2011 \\
\hline $\begin{array}{c}\text { Valor anual da receita bruta } \\
\text { auferida* }\end{array}$ & $\mathrm{R} \$ 36.000,00$ & $\mathrm{R} \$ 60.000,00$ \\
Tributação fixa mensal & $\begin{array}{c}11 \% \text { do salário mínimo } \\
\text { vigente }\end{array}$ & $5 \%$ do salário mínimo vigente \\
\hline
\end{tabular}

Fonte: elaboração das autoras com base nas leis complementares 123/2008 e 139/2011.

Nota: *No caso de início da atividade durante o ano-calendário, será considerado o valor anual dividido por doze meses do ano multiplicados pelo número de meses compreendido entre o início da atividade e o final do respectivo ano-calendário, consideradas as frações de meses como mês inteiro.

Corseuil, Neri e Ulyssea (2013) destacam que, por intermédio de políticas fiscais, como a introdução do Simples Nacional, em 2006, o governo tenta reduzir os encargos tributários e as burocracias que incidem sobre as micro e pequenas empresas, como incentivo ao desenvolvimento empresarial. Os autores expressam a importância desses incentivos para a criação de novas empresas formais, retirando a massa da população que trabalha na informalidade, e também como forma de geração de novos postos de trabalho.

Desde 2009, a figura do MEI incentiva empreendedores que possuem negócios de pequeno porte, oferecendo benefícios primordiais para a formalização de seus negócios e recolhimento da contribuição previdenciária. Os autores complementam que o formato do MEI reduz significativamente os custos com formalização e manutenção, facilitando tanto a entrada como a permanência dos indivíduos no meio empresarial. Assim sendo, abriram-se portas para a realização do sonho de um negócio próprio aos que, por possuírem negócios de pequeno porte, atuavam na informalidade, possibilitando, ainda, grandes oportunidades de crescimento. 


\subsubsection{A representatividade do MEI na economia}

A dimensão de trabalhadores que atuam na informalidade não pode ser mensurada. A migração de todos para a formalidade mostra-se inviável devido tanto a questões burocráticas quanto financeiras. É nesse contexto que surge a alternativa para a saída do anonimato, conforme discutem Souza e Schaurich (2011).

O objetivo econômico por trás da instituição do MEI é a captação dessa camada da população que atua na geração de capital, como observam Silva et al. (2010). Os autores afirmam que por trás desse cenário de busca por novas alternativas de ocupação - empresas familiares, serviço autônomo, trabalho domiciliar, vendas diretas, etc. - está a baixa oferta de empregos que concedam garantias e estabilidade.

\subsubsection{O papel do Sebrae em relação ao MEI}

A busca por informações que esclareçam as dúvidas remanescentes aumentou nos escritórios de atendimento do Serviço Brasileiro de Apoio à Micro e Pequena Empresa após a criação da lei regulamentadora, afirmam Silveira e Teixeira (2011), que passou também a formalizar os novos empreendedores.

A atividade do Sebrae visa dar suporte a micro e pequenas empresas como entidades nacionais, e tem por objetivo o estímulo da cultura do empreendedorismo, contribuindo "para melhorar o desenvolvimento socioeconômico, com geração de receita, trabalho, renda e melhores condições de vida para a população" (SILVEIRA; TEIXEIRA, 2011, p. 227).

\section{Métodos e técnicas}

Nesta seção, apresentam-se os procedimentos técnicos utilizados para operacionalizar as informações pesquisadas. Refere-se, portanto, a uma pesquisa aplicada que "[...] objetiva gerar conhecimentos para aplicação prática dirigidos à solução de problemas específicos. Envolve verdades e interesses locais" (PRODANOV; FREITAS, 2013, p. 51).

\subsection{Delineamento da pesquisa}

Em relação aos objetivos, este trabalho é caracterizado como descritivo, quanto aos seus objetivos, este estudo caracteriza-se como descritivo, conforme indicado por Prodanov e Freitas, pois se considera que o estudo descritivo expõe "as 
características de uma determinada população ou fenômeno, demandando técnicas padronizadas de coleta de dados" (2013, p. 127).

\subsection{Abordagem do problema}

A abordagem do problema de pesquisa é feita por intermédio de um estudo quantitativo, que se utiliza de procedimentos de estatística descritiva. Segundo Prodanov e Freitas (2013, p. 69), a pesquisa quantitativa leva em consideração o seu poder de quantificar, tornando assim possível traduzir informações e opiniões em números, para então classificá-las e analisá-las. Sendo assim, esta é uma abordagem que requer o uso de recursos e de técnicas estatísticas, como a porcentagem.

\subsection{Procedimento técnico}

O levantamento de dados foi usado como procedimento técnico, pois, de acordo com Prodanov e Freitas, "[...] esse tipo de pesquisa ocorre quando envolve a interrogação direta das pessoas cujo comportamento desejamos conhecer através de algum tipo de questionário" (2013, p. 57).

\subsection{Universo da pesquisa}

Prodanov e Freitas descrevem que "[...] população (ou universo da pesquisa) é a totalidade de indivíduos que possuem as mesmas características definidas para um determinado estudo. A definição da população-alvo tem uma influência direta sobre a generalização dos resultados" (2013, p. 98).

Assim sendo, a população deste estudo é composta por 4.791 microempreendedores do município de Passo Fundo, segundo dados do Portal do Empreendedor $(2013)^{1}$. Dessa população, calculou-se uma amostra não probabilística por meio da fórmula de Barbetta, que, com 10\% de erro, exige uma amostra de 98 microempresários. Optou-se pelo arredondamento da amostra para cem indivíduos, que foram selecionados pelo critério acessibilidade.

\subsection{Forma de obtenção e operacionalização dos dados}

Para a execução deste estudo, foram coletados dados primários e secundários. Os dados secundários utilizados para caracterizar a socioeconomia do município foram coletados no endereço eletrônico do Instituto Brasileiro de Geografia e Estatística (IBGE). 
Já os dados primários, foram coletados por meio da aplicação de um questionário, baseado em modelo usado pelo Sebrae para análise de perfil, com nove perguntas objetivas, que foi aplicado via telefone a cem microempreendedores passo-fundenses, conforme pode ser visualizado no Apêndice.

\section{Análise dos dados}

A análise está organizada com a apresentação do perfil socioeconômico da cidade de Passo Fundo seguida da apresentação do perfil dos microempreendedores individuais encontrados por meio dos dados coletados.

\subsection{Perfil socioeconômico passo-fundense}

Localizado no Planalto Médio, interior do estado do Rio Grande do Sul, Passo Fundo é a maior cidade do norte do estado, com área de $783,421 \mathrm{~km}^{2}$. O produto interno bruto (Quadro 3) do município é de $\mathrm{R} \$ 4.551 .198$, e a renda per capita é de $\mathrm{R} \$ 24.618,50$. Os setores do comércio e serviços são responsáveis pela maior parte da produção e renda gerada, embora o setor de serviços também gere grande parte dos empregos locais.

Quadro 3 - Produto interno bruto (valor adicionado para o ano de 2010)

\begin{tabular}{|l|c|c|c|}
\hline \multicolumn{1}{|c|}{ Variável } & Passo Fundo & Rio Grande do Sul & Brasil \\
\hline Agropecuária & 72.877 & 8.764 .507 & 105.163 .000 \\
Indústria & 682.059 & 37.475 .448 & 539.315 .998 \\
Serviços & 3.297 .999 & 77.628 .594 & 1.197 .774 .001 \\
\hline
\end{tabular}

Fonte: elaboração das autoras com base em dados do IBGE (2010) .

Segundo dados do Censo 2011, estima-se que a população do município seja de 184.826 habitantes, desse número, 4.706 habitantes são residentes da área rural e 180.120, da área urbana. Entretanto, por ser um polo universitário e um centro comercial do Norte gaúcho, aparenta ser bem mais populoso, pois há um grande fluxo de pessoas que circulam diariamente na cidade em busca de diversos serviços.

Em relação ao microempreendedor individual, desde que a categoria foi criada, seu número tem crescido continuamente. De acordo com dados do Portal do Empreendedor ${ }^{2}$, até o mês de outubro de 2013 já havia mais de 3,5 milhões de novos empresários em todo o país; desses, 205.444 encontravam-se no estado do 
Rio Grande do Sul, e 4.791 no município de Passo Fundo. Estipula-se que para o próximo ano o número de microempreendedores individuais supere o de micro e pequenas empresas no Simples Nacional.

\subsection{Perfil dos microempreendedores individuais de Passo Fundo}

A pesquisa realizada com os microempreendedores individuais considerou uma amostragem aleatória da população do município de Passo Fundo, envolvendo cem microempreendedores individuais, selecionados no banco de dados dos MEIs do Sebrae Passo Fundo. Dentre eles, 56\% dos entrevistados eram mulheres empreendedoras e $44 \%$, homens.

Por conta da flexibilidade de horário, podendo conciliar com outras atividades, como cuidar da casa e dos filhos, além da possibilidade de ter renda própria, as mulheres compõem a maior proporção na modalidade de empresa MEI, em comparação às micro e pequenas empresas, como aponta pesquisa do Sebrae (2012b).

O Quadro 4 apresenta os resultados quanto ao nível de escolaridade dos MEIs entrevistados.

Quadro 4 - Microempreendedores por nível escolaridade

\begin{tabular}{|l|r|}
\hline \multicolumn{1}{|c|}{ Escolaridade } & Total \\
\hline Ensino fundamental incompleto & $14 \%$ \\
Ensino fundamental completo & $20 \%$ \\
Ensino médio incompleto & $3 \%$ \\
Ensino médio completo & $37 \%$ \\
Superior incompleto & $14 \%$ \\
Superior completo & $11 \%$ \\
Pós-graduação & $1 \%$ \\
\hline
\end{tabular}

Fonte: elaboração das autoras com base nos dados da pesquisa (2014).

Com base nessas informações, constata-se que os microempreendedores individuais têm nível médio de escolaridade, ou seja, são pessoas que estudaram até a aquisição de um determinado nível de ensino para realizarem sua atividade, que não, necessariamente, exige nível superior. O estudo do Sebrae (2012b) justifica que, apesar de baixa, a escolaridade do MEI passo-fundense ainda está acima da média nacional, com $26 \%$ de microempreendedores com ensino médio completo. 
Conforme relatório de 2013, elaborado pela Endeavor Brasil (2013), uma organização internacional sem fins lucrativos, $24 \%$ dos empreendedores do país têm formação superior, e, ainda, um em cada três deles pertence a uma família chefiada por um empresário. Dessa forma, com todo o conhecimento e a experiência adquiridos, indivíduos com esse perfil obtêm uma média de renda mensal superior à média mensal brasileira.

Em relação ao ambiente em que os empresários executam suas atividades, destaca-se que $46 \%$ dos MEIs atuam na própria residência, enquanto os estabelecimentos comerciais são locais de atividade para $40 \%$ dos MEIs. O Quadro 5 apresenta todos os locais de atuação mencionados pelos entrevistados.

Quadro 5 - Local de atuação do microempreendedor

\begin{tabular}{|l|r|}
\hline \multicolumn{1}{|c|}{ Local } & Total \\
\hline Casa & $46 \%$ \\
Casa e domicílio ou empresa do cliente & $1 \%$ \\
Domicílio ou empresa do cliente & $11 \%$ \\
Estabelecimento comercial & $40 \%$ \\
Rua & $2 \%$ \\
\hline
\end{tabular}

Fonte: elaboração das autoras com base nos dados da pesquisa (2014).

Isso demonstra que, além dos gastos reduzidos com a formalização e manutenção do cadastro como MEI, é possível desempenhar as atividades na própria residência, favorecendo ainda mais o baixo custo da empresa.

De acordo com informações obtidas no site do Sebrae (2014b), trabalhar em casa é uma opção para a redução de custos e de tempo gastos com deslocamento. Além de ser uma característica, principalmente do MEI, algumas atividades, como artesanato, utilizam esse espaço como ambiente criativo.

Em análise feita sobre a ocupação anterior à adesão ao MEI, destaca-se que $53 \%$ dos empresários atuavam em ocupações formais e com carteira assinada, e $26 \%$ já tinham seu negócio, mas em condição informal (Quadro 6). 
Quadro 6 - Principal ocupação antes da formalização como microempreendedor individual

\begin{tabular}{|l|r|}
\hline \multicolumn{1}{|c|}{ Situação } & Total \\
\hline Desempregado & $7 \%$ \\
Empregado com carteira & $53 \%$ \\
Empregado sem carteira & $13 \%$ \\
Já tinha negócio próprio formalizado & $1 \%$ \\
Conduzia negócio informal entre dois e cinco anos & $2 \%$ \\
Conduzia negócio informal há dois anos ou menos & $2 \%$ \\
Conduzia negócio informal há mais de 5 anos & $22 \%$ \\
\hline
\end{tabular}

Fonte: elaboração das autoras com base nos dados da pesquisa (2014).

Noronha (2003) esclarece que a criação da carteira de trabalho pode ter significados práticos ou simbólicos, tanto como uma garantia dos direitos do trabalhador, quanto como uma demonstração histórica do perfil do trabalhador.

Assim, nota-se que a grande maioria dos MEIs trocou a situação de empregado para se tornar empreendedor, proprietário de um negócio, aproveitando a oportunidade de desenvolvimento profissional e de independência sobre a carreira. De acordo com Corseuil, Neri e Ulyssea (2013), o formato do MEI permite uma redução significativa dos custos com formalização e manutenção, facilitando tanto a entrada como a permanência dos indivíduos no meio empresarial, atuando como uma alternativa de geração de novos postos de trabalho.

No caso dos microempreendedores que, antes da formalização, já tinham empresa, observa-se que a nova condição empresarial, além de impulsionar novos negócios, é uma opção para a saída da informalidade.

A pesquisa demonstrou que o faturamento dessas empresas após a formalização manteve-se estável ou apresentou aumento (Quadro 7), na maioria dos casos, o que é um fator necessário, como observa Alvim (1998), que realiza um estudo sobre os avanços nas micro e pequenas empresas.

Quadro 7 - Alteração no faturamento após ter registro como MEI

\begin{tabular}{|l|c|}
\hline \multicolumn{1}{|c|}{ Situação } & Total \\
\hline Aumento & $34,6 \%$ \\
Diminuição & $7,7 \%$ \\
Sem alteração & $57,7 \%$ \\
\hline
\end{tabular}

Fonte: elaboração das autoras com base nos dados da pesquisa (2014).

A mesma repercussão foi observada em relação ao investimento no negócio pelo proprietário, com um aumento de $46,1 \%$ e sem alteração em 53,9\%. 
Quadro 8 - Alteração no investimento após registro como MEI

\begin{tabular}{|l|l|}
\hline \multicolumn{1}{|c|}{ Situação } & Total \\
\hline Aumento & $46,1 \%$ \\
Sem alteração & $53,9 \%$ \\
\hline
\end{tabular}

Fonte: elaboração das autoras com base nos dados da pesquisa (2014).

Também se verificou que grande parte dos negócios apresentou melhora no controle financeiro. Esse dado sugere que a formalização no MEI transmite confiança e segurança ao empreendedor, que passa a desempenhar melhor seu papel como gestor.

Quadro 9 - Alteração do controle financeiro após registro como MEI

\begin{tabular}{|l|c|}
\hline \multicolumn{1}{|c|}{ Situação } & Total \\
\hline Aumento & $46,1 \%$ \\
Diminuição & $3,9 \%$ \\
Sem alteração & $50 \%$ \\
\hline
\end{tabular}

Fonte: elaboração das autoras com base nos dados da pesquisa (2014).

Com base na teoria de Keynes, pode-se concluir que o incentivo do governo por meio de políticas fiscais para o crescimento da economia gera desenvolvimento e aumento na produção. Aqueles que antes mantinham seus negócios sem registro, agora, incentivados pela formalização, dispõem de melhores recursos para seu desenvolvimento, e, como pessoas jurídicas, poderão se incorporar de forma adequada ao crescimento da economia nacional.

Perguntados sobre o apoio recebido no momento da formalização, a grande maioria, $61 \%$, afirmou ter recebido auxílio do Sebrae. Essa informação merece destaque, pois destoa do perfil nacional (Quadro 10). Estudo recente promovido pelo Sebrae (2012b) mostrou que apenas 20\% dos MEI receberam apoio da entidade e que a maioria, representada por $45 \%$, não recebeu qualquer ajuda.

Quadro 10 - Auxílio para a formalização

\begin{tabular}{|l|c|}
\hline \multicolumn{1}{|c|}{ Ajuda } & Total \\
\hline Não recebeu & $19 \%$ \\
Sebrae & $61 \%$ \\
Contador & $11 \%$ \\
Prefeitura & $1 \%$ \\
Outra empresa & $2 \%$ \\
Amigo ou familiar & $6 \%$ \\
\hline
\end{tabular}

Fonte: elaboração das autoras com base nos dados da pesquisa (2014). 
Por fim, analisou-se a satisfação dos empreendedores enquadrados no MEI. Pois, conforme Corseuil, Neri e Ulyssea (2013), o MEI abriu portas para a concretização do projeto de um empreendimento legalizado àqueles que mantinham negócios de pequeno porte e atuavam na informalidade, possibilitando grandes oportunidades de crescimento. Desse modo, quando se perguntou aos entrevistados se eles recomendariam a formalização como MEI a um empreendedor informal, quase a totalidade afirmou que recomendaria, totalizando $99 \%$, e apenas $1 \%$ não recomendaria.

Assim, observa-se que a formalização como microempreendedor individual é vista como uma grande vantagem e a satisfação com essa condição é praticamente unanimidade.

Em estudo feito pelo Global Entrepreneurship Monitor, o indicador que relaciona empreendedorismo e bem-estar evidenciou resultados semelhantes aos apresentados nesta pesquisa. Conforme descrito no Observatório Internacional do Sebrae (2014a), os empreendedores tendem a ter mais satisfação em sua ocupação do que as pessoas que não estão envolvidas em atividades empreendedoras, pois há valorização da independência e flexibilidade ao se administrar negócio próprio.

\section{Considerações finais}

Este estudo verificou a concepção dos indivíduos diante da sua formalização como microempreendedores individuais em Passo Fundo no ano de 2013. Passo Fundo, por ser a maior cidade da Região Norte do estado do Rio Grande do Sul, é uma das mais desenvolvidas e proporciona um bom desempenho às microempresas individuais, o que se constata pelo grande número de novas empresas enquadradas nesse modelo de pessoa jurídica.

A análise do perfil dos MEI passo-fundenses apresentou, de uma maneira geral, a formalização da empresa, ou seja, um negócio próprio enquadrado nos requisitos jurídicos, beneficiando o crescimento e proporcionando melhorias, visto que o empresário tem mais segurança e confiabilidade para realizar novos investimentos, conquistando crescimento no faturamento.

Outro ponto importante, e que merece destaque dentre os dados observados, é o apoio recebido dos técnicos do Sebrae. Essa entidade tem o compromisso de oferecer apoio para a sustentabilidade das empresas já formalizadas, entretanto, observou-se que o escritório do Sebrae em Passo Fundo dá também suporte às novas empresas desde seu processo de formalização. Dessa forma, constata-se a 
grande relevância de um órgão federal no processo de criação e manutenção dos pequenos negócios.

Conclui-se, assim, que o novo modelo de pessoa jurídica, o microempreendedor individual, foi acertado e é de grande importância para a economia como um instrumento de incentivo ao empreendedorismo e à formalização. Fato que pode ser comprovado pela satisfação dos empresários que recomendam a migração para o enquadramento como MEI a outros trabalhadores em situação informal, devido aos resultados positivos atingidos com a empresa em situação legalizada.

Como esse trabalho não objetivou esgotar a temática, propõe-se que o estudo seja ampliado, com a finalidade de traçar-se um perfil dos microempreendedores individuais passo-fundenses melhorado e de acompanha-los ao longo da expansão dos seus negócios. Além disso, observa-se a necessidade de ampliar o estudo a fim de investigar os principais motivos que levaram os microempresários a buscar a formalização. 


\title{
The socioeconomic profile of passofundenses MEIS: an analysis in the year 2013
}

\begin{abstract}
This article has the aim to verify the conception of the individuals on the formalization of the single entrepreneurs in Passo Fundo in 2013 Considers the topic relevant in its role to boost regional development and describes the impact of this public policy in this city. With quantitative research, it was verified the satisfaction of new entrepreneurs. The survey reached a random sample of 100 respondents from Passo Fundo. Respondents were contacted by telephone and the data were tabulated with help of simple descriptive statistics. In the results, it was evident the positive satisfaction of the owners of the business and in the profile analysis, it was showed that the single entrepreneurs are a tool to encourage entrepreneurship and formalization.
\end{abstract}

Keywords: Single entrepreneur. Formalization. Satisfaction.

\section{El perfil socioeconómico de MEIS passofundenses: un análisis en el año 2013}

\section{Resumen}

Este artículo tiene como objetivo verificar el diseño de los individuos en la formalización de los microempresarios individuales en Passo Fundo en 2013. Considera que el tema es relevante en su papel para impulsionar el desarrollo regional y describir el impacto de las políticas públicas en esta ciudad. Con la investigación cuantitativa, se encontró la satisfacción de los nuevos empresarios. El estudio llegó a una muestra aleatoria de 100 entrevistados en Passo Fundo. Se llegó hasta los entrevistados por teléfono y los datos fueron tabulados con la ayuda de las estadísticas descriptivas simples. En los resultados, se hizo evidente la satisfacción positiva de los dueños de negocios y análisis de perfil mostró que el microempresario individual es una herramienta para fomentar el espíritu empresarial y la formalización.

Palabras clave: Microempresario individual. Formalización. Satisfacción. 


\section{Notas}

1 <http://www.portaldoempreendedor.gov.br/estatistica/relatorios-estatisticos-do-mei>.

2 <http://www.portaldoempreendedor.gov.br/estatistica/relatorios-estatisticos-do-mei>.

\section{Referências}

ALVIM, Paulo C. R. C. O papel da informação no processo de capacitação tecnológica das micro e pequenas empresas. Ciência da Informação, Brasília, v. 27, n. 1, p. 28-35, jan./abr. 1998. Disponível em: <http://www.scielo.br/pdf/ci/v27n1/04.pdf>. Acesso em: 23 nov. 2013.

BRASIL. Lei Complementar 128, de 19 de dezembro de 2008. Altera a Lei Complementar $\mathrm{n}^{\mathrm{0}}$ 123, de 14 de dezembro de 2006, altera as Leis $n^{\circ}$ 8.212, de 24 de julho de 1991, 8.213, de 24 de julho de 1991, 10.406, de 10 de janeiro de 2002 - Código Civil, 8.029, de 12 de abril de 1990, e dá outras providências. Diário Oficial [da] República Federativa do Brasil, Brasília, DF, 22 dez. 2008. Disponível em: <http://www.receita.fazenda.gov.br/Legislacao/LeisComplementares/2008/ leicp128.htm>. Acesso em: 10 set. 2013.

. Lei nº 10.406, de 10 de janeiro de 2002. Institui o Código Civil. Diário Oficial [da] República Federativa do Brasil, Brasília, DF, 11 jan. 2002. Disponível em: <http://www.planalto.gov. br/ccivil_03/leis/2002/110406.htm>. Acesso em: 10 set. 2013.

CARVALHO, José L. et al. Fundamentos de economia: macroeconomia. São Paulo: Cengage Learning, 2008. v. I.

CORSEUIL, Carlos Henrique L.; NERI, Marcelo C.; ULYSSEA, Gabriel L. Uma análise exploratória dos efeitos da política de formalização dos microempreendedores individuais. Mercado de Trabalho Conjuntura e Análise: Instituto de Pesquisa Econômica Aplicada; Ministério do Trabalho e Emprego, Brasília, v. 54, n. 18, p. 32-41, fev. 2013. Trimestral. Disponível em: <http:// www.ipea.gov.br/portal/images/stories/PDFs/mercadodetrabalho/bmt54_completo1.pdf $>$. Acesso em: 13 set. 2013.

COSTA, Márcia da Silva. Trabalho informal: um problema estrutural básico no entendimento das desigualdades na sociedade brasileira. Caderno Crh, Salvador, v. 23, n. 58, p. 171-190, 2010. Disponível em: <http://www.scielo.br/pdf/ccrh/v23n58/v23n58a11.pdf>. Acesso em: 10 abr. 2013.

ENDEAVOR BRASIL. Empreendedores brasileiros: perfis e percepções 2013. Disponível em: <http://info.endeavor.org.br/relatorio-empreendedores-brasileiros-perfis $>$. Acesso em: 6 jan. 2015 .

FARIA, A. Nogueira de. Estrutura das organizações econômicas. Rio de Janeiro: Record, 1960.

INSTITUTO BRASILEIRO DE GEOGRAFIA E ESTATÍSTICA . Produto Interno Bruto dos Municípios. 2010. Disponível em: <http://cod.ibge.gov.br/5QW6>. Acesso em: 20 jun. 2013.

INSTITUTO BRASILEIRO DE GEOGRAFIA E ESTATÍSTICA. Censo 2011. Rio de Janeiro, 2011. Disponível em: <http://cod.ibge.gov.br/A78>. Acesso em: 20 jun. 2013.

KEYNES, John M. The general theory of employment, interest and money. Cambridge: Macmilian. v. 7, 1936.

KISHTAINY, Niall et al. O livro da economia. 2. ed. São Paulo: Globo, 2013. 
MENEGUIN, Fernando B.; BUGARIN, Maurício S. A informalidade no mercado de trabalho e o impacto das instituições: uma análise sob a ótica da teoria dos jogos. Economia Aplicada, São Paulo, v. 12, n. 3, p. 341-363, jul./set. 2008. Disponível em: <http://www.scielo.br/pdf/ecoa/v12n3/ v12n3a01.pdf>. Acesso em: 26 mar. 2013.

NORONHA, Eduardo G. "Informal”, ilegal, injusto: percepções do mercado de trabalho no Brasil. Revista Brasileira de Ciências Sociais, São Paulo, v. 18, n. 53, p. 111-179, 2003. Disponível em: <http://www.scielo.br/pdf/rbcsoc/v18n53/18081.pdf>. Acesso em: 7 abr. 2013.

PRODANOV, Cleber C.; FREITAS, Ernani C. Metodologia do trabalho científico: métodos e técnicas da pesquisa e do trabalho acadêmico. 2. ed. Novo Hamburgo: Feevale, 2013.

SASAKI, Maria Amélia; VASQUES-MENEZES, Ione. Trabalhador informal e Previdência Social: o caso dos trabalhadores por conta própria de Brasília, DF. Política \& Sociedade, Florianópolis, v. 11, n. 21, p. 173-197, 2012. Disponível em <http://www.periodicos.ufsc.br/index.php/ politica/article/viewFile/2175-7984.2012v11n21p173/22665> Acesso em: 31 mar. 2013.

SCHWINGEL, Inês; RIZZA, Gabriel. Políticas públicas para formalização das empresas: Lei Geral das Micro e Pequenas Empresas e iniciativas para a desburocratização. Mercado de Trabalho Conjuntura e Análise: Instituto de Pesquisa Econômica Aplicada; Ministério do Trabalho e Emprego, Brasília, v. 54, n. 18, p. 47-56, fev. 2013. Trimestral. Disponível em: <http://www. ipea.gov.br/portal/images/stories/PDFs/mercadodetrabalho/bmt54_completo1.pdf >. Acesso em: 13 set. 2013.

SERVIÇO BRASILEIRO DE APOIO À MICRO E PEQUENA EMPRESA. Relatório global 2013. Global Entrepreneurship Monitor. Observatório internacional Sebrae. 2014a. Disponível em: <http://ois.sebrae.com.br/publicacoes/gem-global-report/>. Acesso em: 6 jan. 2015.

. Negócio em casa é realidade para milhões de brasileiros. Portal Sebrae. 2014b. Disponível em: <http://www.sebrae.com.br/sites/PortalSebrae/noticias/Neg\%C3\%B3cio-em-casa-\%C3\%A9-realidade-para-milh\%C3\%B5es-de-brasileiros>. Acesso em: 6 jan. 2015.

. Cartilha para registro de empresa. Porto Alegre: Sebrae, 2012a.

. Perfil do microempreendedor individual 2012. Série Estudos e Pesquisas. 2012b. Disponível em: <http://bis.sebrae.com.br/GestorRepositorio/ARQUIVOS_CHRONUS/bds/bds.nsf/a715 1751f28145b2dfddcb2cb8833d4f/\$File/4304.pdf>. Acesso em: 8 out. 2013.

SILVA, Alessandra Brasiliano et al. Um estudo sobre a percepção dos empreendedores individuais da cidade de Recife quanto à adesão à Lei do Microempreendedor Individual (Lei MEI nº128/2008). Revista da Micro e Pequena Empresa, Campo Limpo Paulista, v. 4, n. 3, 2010. Disponível em: <http://www.faccamp.br/ojs/index.php/RMPE/article/view/183>. Acesso em: 3 set. 2013.

SILVA, Jorge Luiz Teles da et al. A informalidade no mercado de trabalho brasileiro e as politicas públicas do governo federal. Estudo elaborado para a reunião de ministros do Trabalho do Mercosul, Bolívia e Chile. Observatório do Mercado de trabalho. Brasília: Ministério do Trabalho e Emprego, out. 2002. Disponível em: <http://portal.mte.gov.br/data/files/FF8080812BA5F4B7012BABBAC51731E4/Informalidade2.pdf>. Acesso em: 28 mar. 2013.

SILVEIRA, Jane P.; TEIXEIRA, Milton R. C. Empreendedor individual e os impactos pós-formalização. Revista do Núcleo Interdisciplinar de Pesquisa e Extensão, Patos de Minas, v. 1, n. 8, p. 223-252, jul. 2011. 
SOUZA, Roberto F.; SCHAURICH, Cleiva M. Empreendedor individual: impactos financeiros para o Brasil. Revista Científica da Ajes, Juína, v. 2, n. 4, 2011. Disponível em: <http://www.revista.ajes.edu.br/arquivos/artigo_20110515175559.pdf http://www.revista.ajes.edu.br/index.php/ RCA/article/view/61/pdf >. Acesso em: 15 maio 2013.

ULYSSEA, Gabriel. Informalidade no mercado de trabalho brasileiro: uma resenha da literatura. Revista de Economia Política, São Paulo, v. 26, n. 4 (104), p. 596-618, 2006. Disponível em: <http://www.scielo.br/pdf/rep/v26n4/08.pdf>. Acesso em: 31 mar. 2013.

ZEN, Aurora C.; FRACASSO, Edi M. Quem é o empreendedor? As implicações de três revoluções tecnológicas na construção do termo empreendedor. Revista de Administração Mackenzie, São Paulo, v. 9, n. 8, Edição Especial, p. 152-161, nov./dez. 2008. Disponível em: <http://www3.mackenzie.br/editora/index.php/RAM/article/view/213/213>. Acesso em: 30 maio 2013. 


\section{Apêndice}

\section{Questionário aplicado aos microempreendedores individuais de Passo Fundo}

1 - O(a) Sr(a). está em atividade como microempreendedor individual?

( ) Sim. ( ) Não (se não, parar entrevista aqui).

2 - Onde o(a) $\operatorname{Sr}($ a). opera o seu negócio?

( ) Na minha casa.

( ) Em estabelecimento comercial.

( ) Na rua.

( ) No domicílio ou empresa do cliente.

3 - Até que ano o(a) $\operatorname{Sr}(a)$ estudou?

( ) Sem educação formal.

( ) Ensino fundamental incompleto.

( ) Ensino fundamental completo.

( ) Ensino médio ou ensino técnico incompleto.

( ) Ensino médio ou ensino técnico completo.

( ) Ensino superior incompleto.

( ) Ensino superior completo.

( ) Pós-graduação, estudos e pesquisas.

4 - Que outra fonte de renda, além da sua atividade como microempreendedor individual, o(a) $\operatorname{Sr}(a)$. possui?

( ) Não possuo nenhuma outra fonte de renda.

( ) Tenho um emprego (fixo ou não).

( ) Tenho outro negócio por conta própria (fixo ou não).

( ) Recebo pensão.

( ) Recebo aposentadoria.

( ) Recebo ajuda financeira de parentes ou amigos. 
5 - Qual era a sua principal ocupação antes de se registrar como microempreendedor individual?

( ) Estava desempregado(a). [pula para a questão 7]

( ) Estava empregado(a) sem carteira. [pula para a questão 7]

( ) Estava empregado(a) com carteira. [pula para a questão 7]

( ) Já tinha meu negócio e já era formalizado. [pula para a questão 7]

( ) Já tinha o meu negócio há 2 anos ou menos, mas era informal.

( ) Já tinha o meu negócio há entre 2 e 5 anos, mas era informal.

( ) Já tinha o meu negócio há mais de 5 anos, mas era informal.

6 - (para os que já tinham um negócio informal) Após ter se registrado como microempreendedor individual, o que aconteceu com:

O faturamento do seu negócio?

Aumento ( ) Sem mudança ( ) Diminuição ( ) Não se aplica ( )

Seus investimentos no seu negócio?

Aumento ( ) Sem mudança ( ) Diminuição ( ) Não se aplica ( )

O controle financeiro do seu negócio?

Aumento ( ) Sem mudança ( ) Diminuição ( ) Não se aplica ( )

7 - $\mathrm{O}(\mathrm{a}) \mathrm{Sr}(\mathrm{a})$. teve ajuda para se formalizar como microempreendedor individual?

( ) Não.

( ) Sim, de um contador.

( ) Sim, de um amigo ou familiar.

( ) Sim, do Sebrae.

( ) Sim, de outra empresa.

Outro:

8 - $\mathrm{O}$ (a) $\operatorname{Sr}(\mathrm{a})$. recomendaria a formalização como microempreendedor individual para alguém que tenha um negócio informal (sem CNPJ)?

( ) Sim.

( ) Não.

9 - Gênero:

( ) Masculino ( ) Feminino 